\title{
Escorpionismo na zona rural de Teresina, Estado do Piauí: relato de casos de envenenamento
}

\author{
Scorpionism in the rural zone of Teresina, State of Piauí: \\ relate of envenomation cases
}

Senhor Editor:

No Brasil, o acidente escorpiônico constitui um problema atual de saúde pública, não só pela alta incidência em determinadas regiões, como pela sua potencialidade em ocasionar quadros graves, às vezes fatais, principalmente em crianças ${ }^{45}$. No Estado do Piauí, nenhum caso de escorpionismo havia sido relatado até o momento.

Realizamos uma entrevista com dois moradores da zona rural de Teresina que sofreram acidentes com escorpiões a fim de sabermos a espécie causadora e as manifestações do envenenamento. A identificação dos escorpiões foi feita comparando-se as descrições fornecidas pelos moradores com chaves de identificação propostas ${ }^{236}$.

0 primeiro acidente ocorreu com uma mulher de 54 anos no dia 14 de fevereiro de 2004. A paciente foi encaminhada ao hospital com dor local de forte intensidade, agitação, sialorréia, taquicardia, visão embaçada, lacrimejando, espasmos musculares e hipotensão arterial. Ficou em observação no hospital, onde não havia soro anti-escorpiônico, por dois dias. Uma coleta na área da ocorrência do acidente levou à captura de sete espécimes, todos Rhopalurus agamemnon (C.L. Koch, 1839).

0 segundo acidente ocorreu com um jovem de 18 anos no dia três de outubro de 2004 . 0 paciente, atingido no $2^{\circ}$ quirodáctilo, foi socorrido precocemente e apresentava-se com dor local intensa, sialorréia, sonolência e dor irradiada no ombro direito. Ficou em observação no hospital por 24 horas após receber soro anti-escorpiônico. Não levou o escorpião para identificação, mas o descreveu com características similares a Rhopalurus agamemnon.
Os dois pacientes foram atendidos precocemente, lavaram o local da picada, não fizeram incisões ou torniquetes e não tomaram medicamento sem prescrição médica.

Rhopalurus agamemnon, é um animal que se distribui pelos Estados do Piauí, Goiás, Bahia, Ceará, Mato Grosso e Pernambuco ${ }^{13}$. É caracterizado pelo grande tamanho, podendo chegar a $110 \mathrm{~mm}$ de comprimento total, e possui coloração de modo geral marrom, pernas amareladas, pedipalpos com tons marrons/amarelados, segmentos metassomais I a III amarelos/marrons, IV e V mais escuros ou quase negros. São, geralmente, encontrados em vegetações abertas ${ }^{236}$. Há espécimes registrados para Piracuruca, Castelo do Piauí, União, Teresina, José de Freitas e São Raimundo Nonato, no Estado do Piauí.

\section{REFERÊNCIAS}

1. Lenarducci ARIP, Pinto-da-Rocha R, Lucas SM. Descrição de uma nova espécie de Rhopalurus Thorell, 1876 (Scorpiones, Buthidae) do nordeste brasileiro. Biota Neotropica, Campinas, volume 5, número 1A, p. 173-180, 2005.

2. Lourenço WR. Scorpions of Brazil. Les Éditions de ITf, Paris, 2002.

3. Lourenço WR. Scorpiones. In: Adis J (ed) Amazonian Arachnida and Myriapoda. Identification keys to all classes, orders, families, some genera and lists of known terrestrial species. Pensoft Publishes, Moscow, 2002.

4. Lourenço WR, Eickstedt VRD. Escorpiões de importância médica. In: Cardoso JLC, França FOS, Wen FH, Málaque CM, Haddad Jr (eds) Animais peçonhentos no Brasil: Biologia, clínica e terapêutica dos acidentes. Editora Sarvier, São Paulo, p.182-197, 2003.

5. Ministério da Saúde. Fundação Nacional de Saúde. Manual de diagnóstico e tratamento de acidentes por animais peçonhentos. Ministério da Saúde, Brasília, 2001.

6. Polis GA. The Biology of Scorpions. Stanford University Press, Stanford, 1990.

\section{Leonardo Sousa Carvalho ${ }^{1}$, Marcos Pérsio Dantas Santos ${ }^{2}$ e Sidclay Calaça Dias ${ }^{1}$}

\footnotetext{
1. Laboratório de Aracnologia, Museu Paraense Emílio Goeldi, Laboratório de Aracnologia, Belém, PA. 2. Laboratório de Zoologia, Departamento de Zoologia, Universidade Federal do Piauí, Teresina, PI.

Endereço para corrrespondência: Sr. Leonardo Sousa Carvalho. Laboratório de Aracnologia/Museu Paraense Emílio Goeldi. Campus de Pesquisa. Av. Perimetral 1901, Caixa Postal 399, 66017-970 Belém, PA.

e-mail: leosc_fla@yahoo.com.br

Recebido em:16/01/2007

Aceito em: 23/05/2007
} 